\title{
Density Dependent Competitive Interactions between Weedy Rice (Oryza sativa F. Spontaneae) and Cultivated Rice (Bg 379-2) in Sri Lanka
}

\author{
Karunarathna KDK, Weerakoon SR and Somaratne S \\ Department of Botany, Open University of Sri Lanka, Sri Lanka
}

\begin{abstract}
Weedy rice (Oryza sativa f. spontaneae) is a recently emerged major threat in many rice-growing areas in tropical Asia including Sri Lanka since 1990s. Though there are scientific investigations on origin, diversity, distribution and controlling technique of weedy rice in regional and global scales, studies on the interactions between weedy rice and cultivated rice varieties under local situations are limited. A green-house experiment was conducted at the Open University, Nawala, Sri Lanka (30oC, 40\% humidity) in 2015 using an improvedcultivated rice variety (Bg379-2) with varying percentages of cultivated: a black-hulled weedy rice bio-type (0, 20, 40, 6080100 /pot). Influence of weedy rice on growth and yield of Bg379-2 was assessed by measuring plant height and number of tillers through 2, 4, 6 and 8 weekly. Dry shoot-and root- biomass of uprooted plants at 8 weeks after sowing (8WAS)were determined through oven-dried to a constant weight at70 ${ }^{\circ} \mathrm{C}$ for 72 hrs and weighed to the nearest $0.01 \mathrm{~g}$. Yield components of Bg379-2 including mean weight of $100 \mathrm{grains} / \mathrm{plant}$, number of panicles/plant, number of grains/panicle and yield weight/plant were calculated. Data were statistically analyzed using SAS Ver. 9.0. Significant interactions between weedy rice bio-type and Bg379-2 were apparent after 6 weeks after sowing (WAS). A yield loss of 30\% was observed even at a percentage of 20 of weedy rice at 20 /pot. The competition of weedy rice resulted in 90\% loss of yield of variety Bg379-2at $80 \%$ plants/pot. For the purpose of generalization, further research is recommended to determine the effect of weedy rice density on growth and yield components of different new improved rice varieties.
\end{abstract}

KEYWORDS: Competition, Oryza sativa f. spontaneae, Yield loss, Sri Lanka, Weedy rice

Corresponding author: S. R.Weerakoon, email: shyamaweerakoon@gmail.com 


\section{INTRODUCTION}

Rice (Oryza sativa L.) is one of the major staple food crops cultivated throughout the world and is mainly important in Asia where approximately $90 \%$ of world's rice is produced and consumed (Zeigler and Barclay, 2008). Improving the productivity of rice in terms of quality and quantity has become very important as it is necessary to feed nearly half of the world's population. Weedy rice (Oryza sativa L. f. spontaneae), botanically classified as the same species as cultivated rice of family Poaceae is a wild plant closely associated with cultivated rice and is widely distributed in rice growing areas all over the world (Ferrero et al., 1999; Mortimer et al., 2000).

Weedy rice is categorized as one of the noxious weeds infesting rice fields worldwide (Gealy et al., 2002; Delouche et al., 2007). It is annually grown and self-pollinating plant that is conspecific to cultivated rice and is capable of spreading rapidly through long-distance when mixed with weedy rice seeds (He et al., 2014). Weedy rice appears to possess a wide variation in morphological characters which has led to much speculation about the origin of these weeds.

It has become a major threat in many rice growing areas. It is widely distributed in rice growing areas in the world, in particular, in South and South-East Asia, South and North America, and Southern Europe (Mortimer et al., 2000; Noldin, 2000; Chauhan and Johnson, 2010a; Chauhan, 2012a) and hassled to high production costs as well as considerable yield reduction (Azmi and Karim, 2008). In general, weedy rice diminishes farmers' income both quantitatively and qualitatively (Mortimer et al., 2000). At present, weedy rice has reached to a higher level of competitive ability to threaten the sustainability of rice cultivation especially in Asian countries.

The flower morphology and brief period of pollen viability of cultivated rice is an adaptation to being a predominantly self-pollinating crop. The wild rice, on the other hand, differ from cultivated rice by having a greater ability for outcrossing having longer styles, stigmas, filaments and anthers, and pollen viability as twice as cultivated rice (Oka, 1988). Five wild rice species recorded in Sri Lanka, namely O.nivara, O.rufipogon, O.echingeri, O.grnulate and $O$. rhizomatis have been reported as weedy forms in cultivated rice fields (Siwakoti and Tiwari, 2007). Although systematically the weedy rice classified under the same species as cultivated rice, weedy rice is strongly characterized by very high seed shattering property and seed dormancy, which apparently enhance the distribution and continuous enrichment of soil seed bank with seeds (Baltazar and Janiya, 2000).

\section{BACKGROUND/ LITERATURE SURVEY}

In Sri Lanka, weedy rice (WR) has become a major problem since late 1990 affecting growth and yield of cultivated rice reaching to $30-40 \%$ yield loss (about 1,600-2,000 kg/ha) despite farmers investing 5000-8000 LKR/ha for herbicides (Marambe and Amarasinghe, 2000; Abeysekera et al., 2010). The growth and competitive ability of weedy rice vary considerably among populations due to differences in plant height, leaf area or biomass (Chauhan and Johnson, 2010a). According to Smith (1988), at the density of one to three plants per square meter of WR is the threshold infestation level that is required to prevent yield losses in rice, whereas the corresponding density for barnyard grass (E. crusgalli) is estimated at 5-10 plants/m².

As labor and or water costs rises in many Asian countries, transplanting of rice seedlings, the well adapted crop establishment method, has being replaced by direct seeding (DS) where the emergence of weedy rice assumed to have initiated (Pandey and Velasco, 2005). Direct seeded rice ecosystems provide environments 
Density Dependent Competitive Interactions between Weedy Rice and Cultivated Rice

conducive for the emergence and propagation of weedy rice as compared to transplanted rice having standing water that suppress the emergence of weedy rice at the early stages of the crop (Chauhan and Johnson, 2010b). Furthermore, selective herbicides to control weedy rice are yet to be identified. Thus, managing weedy rice is a challenging problem for farmers because of its morphological and physiological similarities to cultivated rice

Weedy rice can cause severe yield losses to cultivated rice in relation to the density, type of weedy plants and cultivated varieties (Fischer and Ramirez, 1993; Eleftherohorinos et al., 2002). In Malaysia weedy rice caused rice yield loss of $60 \%$ to $80 \%$ under moderate (15-20 weedy rice panicles $\left./ \mathrm{m}^{2}\right)$ to high (21-30 panicles $/ \mathrm{m}^{2}$ ) infestations (Azmi and Karim, 2008). In Malaysia, red rice was first detected in rice fields in 1988 (Wahab and Suhaimi, 1991), and economic loss in the area was high (Azmi and Karim, 2008). A similar loss in cultivated rice due to a weedy rice variant infestation has been reported in India (Abraham and Jose, 2014). Short varieties are usually more susceptible to weedy rice competition than tall ones (Kwon et al., 1991a). Some studies have been conducted to assess the effects of different weed densities. Abud (1989) reported that density of 11 weedy rice plants $\mathrm{m}^{-}$ ${ }^{2}$ led to considerable yield loss of $43 \%$.

Although a number of scientific investigations on weedy rice origin, diversity, distribution and technique for control are available, researches pertaining to interactions of weedy rice with new improved rice varieties under local conditions are inadequate. In spite of the importance of weedy rice as a noxious weed, there is an insufficiency of information available in Asia on the magnitude of the effect of yield and other growth parameters of cultivated rice due to weedy rice.

An expansion in the area under direct-seeded rice systems in the near future in Asia is expected due to labor and water deficiency
(Chauhan, 2012b). In these systems, weedy rice infestation will increase because of the absence of the suppressive effect of standing water during crop emergence. Therefore, it is important to study the effect of the degree of weedy rice infestation on the growth and yield of cultivated rice. The proper understanding of the density dependent competitive interaction between cultivated and weedy rice is essential in providing baseline information for farmerawareness programs and strengthening farmer capabilities of weedy rice management in rice fields in particular, for the preparation of guidance and justification of the costs of weedy rice prevention and control measures. The present study was carried out with the objective to quantify the competitive performance between weedy rice and anew improved rice variety as a function of rice yield and selected growth parameters.

\section{MATERIALS AND METHODS}

Experiments were conducted at the Open University, Nawala, Sri Lanka in 2015. The improved-cultivated rice variety Bg379-2 and black-hulled weedy rice (WR) bio-type collected from Ampara District in Southern Province of Sri Lanka served as experimental material. The soils were collected from the rice fields where weedy rice bio-type was collected. Collected soils were passed through a $2 \mathrm{~mm}$ sieve and placed in cement pots of $30 \times 30 \times 30$ $\mathrm{cm}$. There were no holes in the pots. The weedy rice and cultivated rice (cv. Bg379-2 and - a commonly grown variety in Ampara District and black hulled WR bio-type) were grown in a replacement series design at proportions (cultivated rice : weedy rice) (\%) of $0: 100$, 20:80, 40:60, 60:40, 80:20 and 100:0 with nine plants in a pot. The experiment included a total of six treatments and each treatment was represented by five replicates (five pots) of nine plants which were arranged in a random complete design. Thus, the total number of replicates included in the trial was 270 . The population was grown in $100 \%$ proportion 
considered as no competition and the rest represent the different degrees of competitions. Planting of WR bio types and cultivated rice plants in a pot is shown in Figure 1.

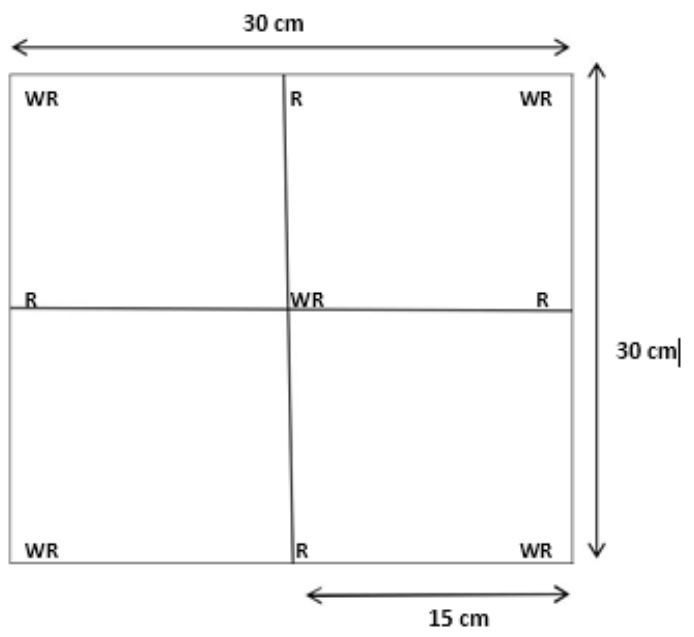

Figure 1. A pot representing the placement of weedy rice plants and Bg379-2 rice plants ( $\mathrm{R}$ Bg379-2, WR - Weedy rice bio-type)

The plants were fertilized with urea at a rate of $100 \mathrm{~kg} / \mathrm{ha}$ at 14, 28, and 60 days after sowing and pots were maintained at field capacity by irrigating regularly. After crop emergence, $2 \mathrm{~cm}$ depth of water was maintained until crop maturity. Insect or disease problems were not observed during the experimental period and, therefore no control measures were undertaken.

The influence of weedy rice plants on growth and development of Bg379-2 was assessed through 2, 4, 6 and 8 weekly measurements of important agro-morphological characters, plant height and number of tillers. The dry shoot- and root- biomass were determined through oven drying at $70{ }^{\circ} \mathrm{C}$ for $72 \mathrm{~h}$ of uprooted randomly selected plants at 8 weeks after sawing (WAS). At harvesting stage, the yield components of both Bg379-2 and WR bio-type, including 100 grain weight/plant, number of panicles/plant, number of grains/panicle and yield weight/plant were estimated (data were not given for WR biotype). Collected data were statistically analyzed using SAS Ver. 9.0, (2002). One way analysis of variance (ANOVA) carried out comparing the treatment means were compared using of least significant difference (LSD) at $\mathrm{p}=0.05$.

\section{RESULTS AND DISCUSSION}

The effect of weedy rice density on Bg379-2 was evidenced by the significant differences observed in plant height and tiller number from 6 WAS onwards (Table 1). Comparatively, there was a considerable decrease in plant height at 8 WAS (from $81.9 \mathrm{~cm}$ in the control to $64.9 \mathrm{~cm}$ at the highest weedy rice density: $80 \%$ of weedy rice plant/pot) and number of tillers/plant (from 35 in the control to 22.1 at the highest weedy rice percentage; $80 \%$ weedy rice plant/pot). Even at the lowest weedy rice density tested (20\% of weedy rice plants/ pot), the effect is apparent in both parameters.

Table 1. Plant height of Bg379-2 grown under different densities of weedy rice at different weeks after sowing (WAS). Means (+ SE) within a column followed by the same letter(s) are not significantly different at $\mathrm{p} \leq 0.05$.

\begin{tabular}{|c|l|l|l|r|}
\hline & \multicolumn{5}{|c|}{ Plant Height (cm) } \\
\hline $\begin{array}{l}\text { Weedy rice: } \\
\text { cultivated } \\
\text { rice (\%) }\end{array}$ & 2WAS & 4WAS & 6WAS & 8WAS \\
\hline 0 & $27.0(0.31)$ c & $46.4(0.12)$ a & $68.7(0.32)$ a & $81.9(0.23) \mathrm{a}$ \\
\hline 20 & $28.4(0.15)$ a & $45.8(0.21)$ ab & $65.1(0.29) \mathrm{b}$ & $77.1(0.25) \mathrm{b}$ \\
\hline 40 & $28.0(0.47)$ ab & $45.1(0.21) \mathrm{c}$ & $63.9(0.31) \mathrm{c}$ & $76.8(0.23) \mathrm{b}$ \\
\hline 60 & $27.4(0.15) \mathrm{bc}$ & $41.2(0.12) \mathrm{d}$ & $58.6(0.15) \mathrm{d}$ & $70.9(0.29) \mathrm{c}$ \\
\hline 80 & $27.3(0.15) \mathrm{c}$ & $45.5(0.26) \mathrm{bc}$ & $56.8(0.31) \mathrm{e}$ & $64.9(0.40) \mathrm{d}$ \\
\hline & & & & \\
\hline $\begin{array}{l}\text { Critical } \\
\text { value }\end{array}$ & 0.7169 & 0.9841 & 0.7648 & 0.7342 \\
\hline
\end{tabular}

In the present study, the varying densities of weedy rice indicated a considerable reduction in growth parameters and yield components of improved-cultivated rice variety Bg379-2 under the green-house conditions. The plant height and number of tillers of rice plants seem to be less affected at $40 \%$ and $80 \%$ of WAS at different percentages of weedy rice/pot. However, the 
Density Dependent Competitive Interactions between Weedy Rice and Cultivated Rice

effect of varying percentages of weedy rice on root and shoot biomass indicated decreasing trends for Bg379-2. This finding agreed with Chauhan (2013) who suggested that the decreasing trends are due to the shading effect of weedy rice, and observed that different sunlight regimes and shoot biomass (stem and leaf biomass) of cultivated rice declined by $57 \%$ and $72 \%$ when grown in $50 \%$ and $75 \%$ of shade, respectively. On this basis, it could be suggested that the decrease of dry matter accumulation in cultivated rice variety Bg379-2 is attributed to competition of

weedy rice over cultivated rice for capturing the light, nutrient and even carbon dioxide.

The effect of weedy rice percentage on Bg379-2 was obvious on root biomass (65\% reduction) than shoot biomass (60\% reduction) at $8 \mathrm{WAS}$ under the density of $80 \%$ of weedy rice plant/pot (Table 2, Figure 2).

Table 2. Root and shoot biomass of Bg 379-2 grown under different densities of weedy rice at 8WAS. Means ( + SE) followed by the same letter(s) in a column are not significantly different at $\mathrm{p} \leq 0.05$

\begin{tabular}{|c|c|c|}
\hline $\begin{array}{c}\text { Weedy rice: } \\
\text { cultivated rice } \\
\text { (\%) }\end{array}$ & $\begin{array}{c}\text { Root biomass } \\
\text { (g/plant) }\end{array}$ & $\begin{array}{c}\text { Shoot biomass } \\
\text { (g/plant) }\end{array}$ \\
\hline 0 & $57.81(0.01) \mathrm{a}$ & $97.28(0.04) \mathrm{a}$ \\
\hline 20 & $43.41(0.03) \mathrm{b}$ & $67.84(0.01) \mathrm{ab}$ \\
\hline 40 & $37.96(0.05) \mathrm{c}$ & $66.38(0.02) \mathrm{b}$ \\
\hline 60 & $35.09(0.03) \mathrm{d}$ & $51.96(0.05) \mathrm{b}$ \\
\hline 80 & $27.2(0.02 \mathrm{e}$ & $50.97(0.04) \mathrm{b}$ \\
\hline Critical value & 8.8074 & 323.66 \\
\hline
\end{tabular}

The effect of density of weedy rice plants on Bg379-2 on the root biomass at 8WAS even under the density of one weedy rice plant/pot suggests that weedy rice roots may exert considerable competitive effect over the improved rice variety and interfere with the nutrient uptake. This finding is further supported by results of detailed comparative study with other weed species as well as with other improved rice varieties carried out by Naderi and Bijanzadeh (2012).

The overall effect of different weedy rice densities on Bg379-2 was more apparent in the relationships observed for yield components; 100 grain weight/plant (Figure 3. A), grains/panicle (Figure 3. B), panicle density (panicles/plant) (Figure 3. C) and yield (Figure 3. D) (Table 3). Even under lower values of WR densities (20\% of weedy rice plants/pot), there were substantial difference in 100 grain weight (ranged from $61.06 \mathrm{~g} /$ plant to $87.55 \mathrm{~g} / \mathrm{plant}$ ), grains/panicle (ranged from 33.0 to 42.0), panicle density (from $20 \%$ of weedy rice/plant to 80 of weedy rice/plant) and yield reducing from $47.76 \mathrm{~g} /$ plant to $68.01 \mathrm{~g} /$ plant. These results indicated that there was a substantial effect of the presence of weedy rice plants on panicle formation and grain filling of the improved rice cultivar, Bg379-2.

The relationship observed between the weedy rice density and the yield of Bg379-2 showed a yield loss of $90 \%$ (calculated from data available in Table 3) at weedy rice density of $80 \%$ of weedy rice plants/pot. Comparatively higher (90\%) yield loss of the cultivated rice even at the weedy rice density at $20 \%$ of weedy rice plants/pot could be attributed to the presence of weedy rice (Figure 3 D).

As present study revealed, the yield loss of the cultivated rice due to the presence of weedy rice is comparatively higher even at weedy rice density at $20 \%$ of weedy rice plants/pot. Similarly, Abud (1989) has made observations with 1 weedy rice plants/pot and observed a yield loss of about 43\%. These evidence suggest farmers to take controlling measures even at the lowest weedy rice density. However, it is proposed to extend this study to other popular improved-cultivated rice varieties to facilitate the understanding of the differential interactions of weedy rice and cultivated rice and to define action thresholds for weedy rice. A study with two weedy rice variants (WR1 and WR2) revealed that, WR1 reduced the grain yield of 
cultivated rice by $30 \%$ and $47 \%$ at densities of $20 \%$ and $80 \%$ of weedy rice plants/pot respectively. The values for WR2 were $66 \%$ and $81 \%$, respectively (Chauhan, 2013). Weedy rice, with its deep root system and height found to interfere with the nutrition and light availability

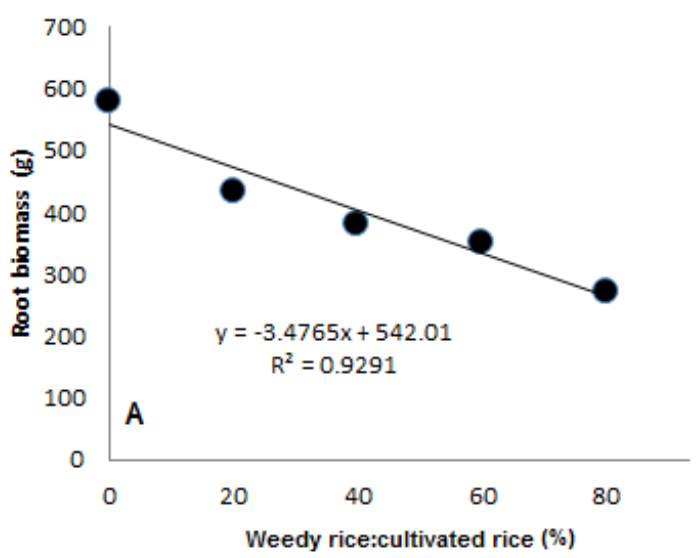

to the new improved rice. In addition, weedy rice, as a newly invading plant to the rice soils may have developed tolerance and adaptability to limited resources for survival and to compete with other plants.

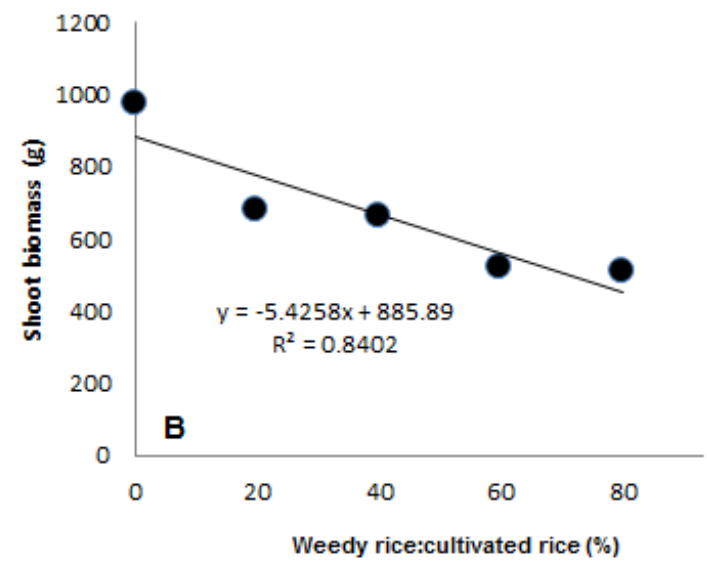

Figure 2. Relationship between the weedy rice: cultivated rice ratio. A. Root biomass and B. Shoot biomass.
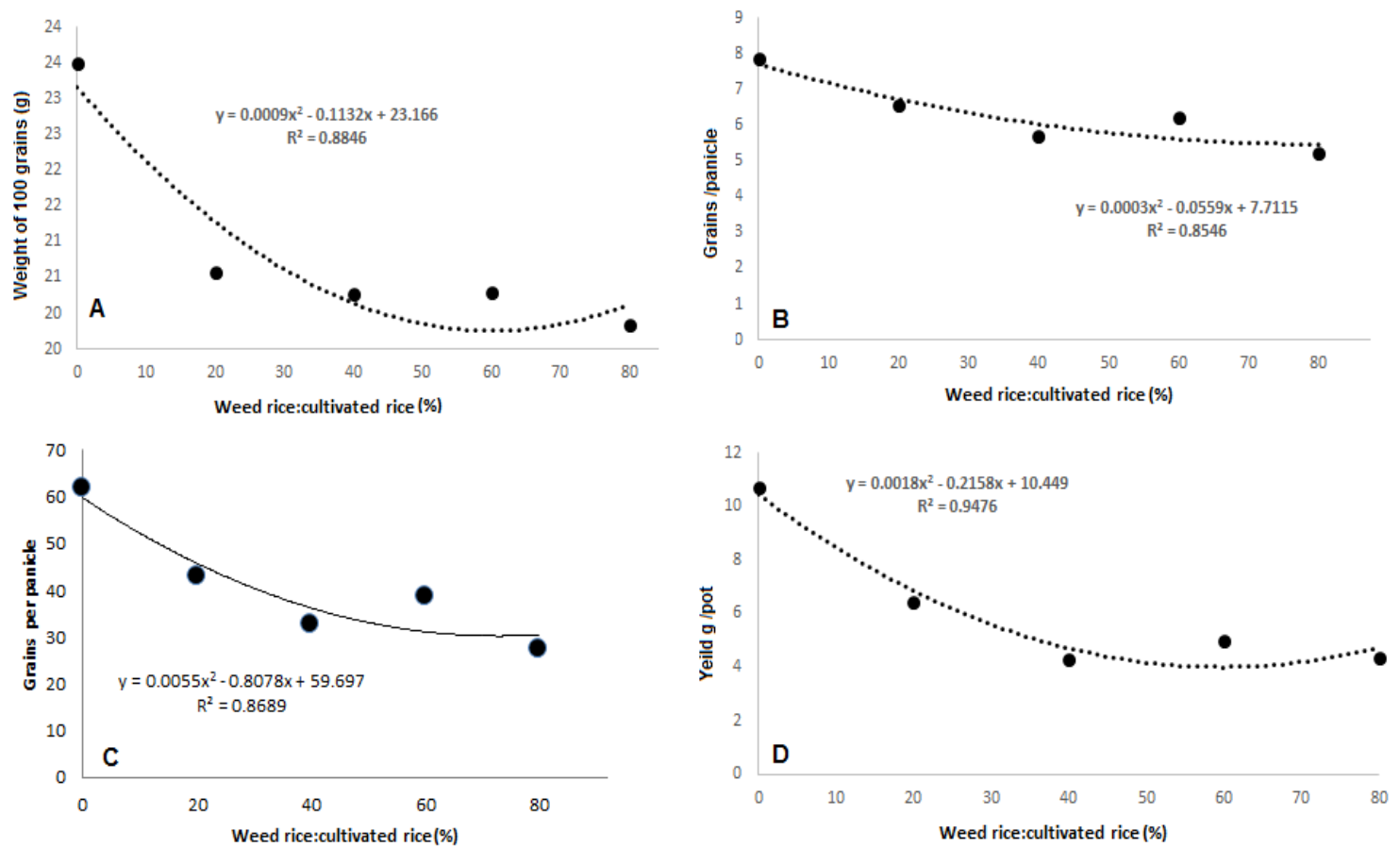

Figure 3. Relationship between the weedy rice: cultivated rice ratio and yield components.

A. 100 grain weight/plant (g/plant), B. Number of grains/panicle,

C. Number of panicles/plant, and D. yield (g/plant) of improved-cultivated rice variety, Bg379-2. 
Density Dependent Competitive Interactions between Weedy Rice and Cultivated Rice

Table 3. Yield components of Bg379-2 grown under different densities of weedy rice.

Means (+ SE) within a column followed by the same letter(s) are not significantly different at $\mathrm{p}=$ 0.05 .

\begin{tabular}{|c|c|c|c|c|}
\hline $\begin{array}{c}\text { Weedy rice: cultivated } \\
\text { rice (\%) }\end{array}$ & $\begin{array}{c}\text { 100 grain weight } \\
\text { (g/plant) }\end{array}$ & Grains/panicle & $\begin{array}{c}\text { Number of } \\
\text { panicles/plant }\end{array}$ & Yield (g/plant) \\
\hline 0 & $87.55(0.01) \mathrm{a}$ & $42.0(0.01) \mathrm{a}$ & $10.0(0.01) \mathrm{a}$ & $68.01(0.01) \mathrm{a}$ \\
\hline 20 & $61.06(0.00) \mathrm{b}$ & $33.0(0.02) \mathrm{ab}$ & $9.0(0.02) \mathrm{b}$ & $47.76(0.01) \mathrm{b}$ \\
\hline 40 & $29.87(0.01) \mathrm{c}$ & $32.0(0.02) \mathrm{ab}$ & $6.0(0.02) \mathrm{d}$ & $21.04(0.02) \mathrm{e}$ \\
\hline 60 & $15.59(0.02) \mathrm{d}$ & $28.0(0.03) \mathrm{b}$ & $8.0(0.03) \mathrm{c}$ & $18.52(0.03) \mathrm{d}$ \\
\hline 80 & $6.97(0.01) \mathrm{e}$ & $27.0(0.05) \mathrm{b}$ & $5.0(0.00) \mathrm{e}$ & $6.27(0.05) \mathrm{c}$ \\
\hline Critical value & 0.51 & 1.71 & 1.46 & 17.33 \\
\hline
\end{tabular}

Several studies have shown that competition effects of rice and weedy rice are also closely related to the duration of interaction (Kwon et al., (1991b). Combining the effects of weedy rice density and duration of competition, Fischer and Ramirez (1993) observed a 50\% yield reduction at 24 weedy rice plants $/ \mathrm{m}^{2}$ competed with the crop during the first 40 days after emergence. With the same initial density, the yield loss reached $75 \%$ in the case of season-long competition. In a green-house experiment, significant effects on rice plant growth were reported only at the competition longer than 70 days, starting from the emergence (Estorninos et al., 2000; Estorninos et al., 2005). In studies of competition using cultivar Mars, inter-varietal competition resulted as being important than intra- varietal competition, with the weedy rice acting as the dominant competitor (Pantone and Baker, 1991). Considering the yield components, the effect of plant density seems to be significant on the number of rice panicles/plant and florets/panicle, while the percent of filled florets and the grain weight do not seem to be influenced by this parameter (Pantone et al. 1992). Eleftherohorinos et al., (2002) have observed that interference between rice and weedy rice commenced three weeks after rice emergence, but was not affected by an increase of the nitrogen rate from 100 to $150 \mathrm{~kg} / \mathrm{ha}$. According to their study a density at 40 weedy rice plants $/ \mathrm{m}^{2}$ resulted in a reduction of $46 \%$ and $58 \%$ in Ariete and Thaibonnet rice varieties, respectively.

\section{CONCLUSIONS/ FUTURE WORK}

The findings of the present study led to conclude that infestation of weedy rice even at low density of 1 weedy rice plant/pot affect the growth of the new improved rice variety, Bg379-2 leading to a considerable loss in yield (30\%). However, further research is needed to determine the impact of crop management on the competitiveness of weedy rice under field conditions representing different climatic conditions.

\section{ACKNOWLEDGEMENTS}

Authors wish to acknowledge the Research Grant provided by the Faculty of Natural Sciences at the Open University of Sri Lanka.

\section{REFERENCES}

ABEYSEKERA ASK, HERATH HMS, WICKREME UB \& JOHNSON DE. Improving crop establishment and reducing loss from weeds in direct-seeded rice in Sri Lanka. Research to Impact:Case studies for Natural Resources Management for Irrigated rice in Asia. 2010; 151-166. IRRI, LosBanos, The Philippines.

ABRAHAM CT \& JOSE N. Weedy rice invasion in rice fields of India and 
management options. Journal of Crop and Weed. 2014; 10(2):365-374.

ABUD JK. Efeitos competitivos do arrozvermelhonos components do rendimento e rendimentodegraosencascana cultivar de arroz BR-IGRA 412. LavouraArrozeira. 1989; 42: 11-12.

AZMI M \& KARIM R. Weedy Rice-Biology, Ecology and Management. MARDI Publications. (2008).

BALTAZAR AM \& JANIYA JD. Weedy Rice in the Philippines. Wild and Weedy Rice in Rice Ecosystems in Asia a Review. (eds B.B.) Baki, D.V. Chin and M. Mortimer. 2000; 75-76. Limited Proceedings No. 2, Los Banos, Philippines: International Rice Research Institute.

CHAUHAN BS \& JOHNSON DE. The role of seed ecology in improving weed management strategies in the tropics Advances in Agronomy. 2010a; 105: 221-262.

CHAUHAN BS \& JOHNSON DE. Weedy rice (Oryza sativa L.). I. Grain characteristics and growth response to competition of weedy rice variants of five Asian countries Weed Science. 2010b; 58: 374-380.

CHAUHAN BS. Weedy rice (Oryza sativa). II. Response of weedy rice to seed burial and flooding depth. Weed Science. 2012a; 60: 385-388.

CHAUHAN BS. Weed Ecology and Weed Management Strategies for Dry-Seeded Rice in Asia. Weed Technology. 2012b; 26: 1-13.

CHAUHAN BS. Effect of weedy rice variants and weedy rice density on growth and yield of two rice cultivars in the Philippines. Canadian Journal of Plant Protection1. 2013; 28-34
DELOUCHE JC, BURGOS NR, GEALY DR, ZORILLA-SAN MG, LABRADA R, LARINDE M \& ROSELL C. Weedy Rices: Origin, Biology, Ecology and Control. FAO Plant Production and Protection Paper, FAO, Rome, Italy. 2007.

ELEFHTEROHORINOS IG, DHIMA KV \& VASILAKOGLOU IB. Interference of red rice in rice grown in Greece. Weed Science. 2002; 50: $167-172$.

ESTORNINOS LE Jr, GEALY DR \& TALBERT RE. Interference between red rice and rice in a replacement series studies. Research Series Arkansas Agricultural Experiment Station. 2000; 463-46.

ESTORNINOS LE Jr, GEALY DR, TALBERT RE, McCLELL REMR. Rice and red rice interference. II. Rice response to population densities of three red rice (Oryza sativa) ecotypes. WeedScience. 2005; 53:683689.

FERRERO A, VIDOTTO F, BALSARI P \& AIROLDI G. Mechanical and chemical control of red rice (Oryza sativa L. var. sylvatica) in rice (Oryza sativa L.) per-planting. Crop Protect. 1999; 18: 245-251.

FISCHER AJ \& RAMIREZ A. Red rice (Oryza sativa): competition studies for management decisions. International Journal of Pest Management. 1993; 39: 133-138.

GEALY DR, TAI TH \& SNELLER CH. Identification of red rice, rice, and hybrid populations using microsatellite markers. Weed Sci. 1993; 50:333-339.

HE Z, JIANG X, RATNASEKERA D, GRASSI F, PERERA U \& LU B-R. Seed mediated gene flow promotes within- population genetic variation of weedy rice: implication for weed management. PLOS One. 2014; 9(12): e112778. 
KWON SL, SMITH RJ Jr. \& TALBERT RE. Interference of red rice (Oryza sativa L.) densities in rice (Oryza sativa L.). Weed Science. 1991a; 39: 169-174.

KWON SL, SMITH RJ Jr. \& TALBERT RE. Interference and duration of red rice (Oryza sativa L.) in rice (Oryza sativa). Weed Science. 1991b; 39:363-368.

MARAMBE B \& AMARASINGHE L. Weedy rice in Sri Lanka. Wild and Weedy Rice in RiceEcosystems in Asia - a review (eds. B.B. Baki, D.V. Chin \& M. Mortimer). International Rice Research Institute, Philippines. 2000; 7982.

MORTIMER M, PANDEY S \& PIGGIN C. Weedy rice: approaches to ecological appraisal and implications for research priorities. Wild and Weedy Rice in Rice Ecosystems in Asia. A review (eds. B.B. Baki, D.V. Chin \& M. Mortimer). International Rice Research Institute, Los Banos, Philippines. 2000; 97-105.

NADERI R \& BIJANZADEH E. Allelopathic potential of leaf, stem and root extracts of some Iranian rice (Oryza sativa L.) cultivars on barnyard grass (Echinochloa crus-galli) growth. Plant Knowledge Journal. 2012; 1:37-40.

NOLDIN JA. Red rice status and management in Americas. Wild and weedy rice in riceecosystems in Asia - a review. (Eds. B.B. Baki, D.V. Chin \& M. Mortimer). Los Baños,Philippines: International Rice Research Institute. 2000; 21-24.

OKA HI. Origin of cultivated rice. Tokyo: Japan Science Society Press. 1988.

PANDEY S \& VELASCO L. Trends in crop establishment methods in Asia and research issues. In: Rice is Life: Scientific Perspectives for the $21^{\text {st }}$ Century. Proceeding of the Word Rice ResearchConference, 4-7 November 2004, Tsukuba, Japan. 2005; 178-181.
PANTONE DJ \& Baker JB. Weed-crop competition models and response-surface analysis of red rice competition in cultivated rice: a review. Crop Science. 1991; 31 (5): 11051110.

PANTONE DJ, BAKER JB \& JORDAN PW. Path-analysis of red rice (Oryza sativa L.) competition with cultivated rice. Weed Science. 1992; 40: 313-319.

SAS. SAS Institute Inc. SAS/STAT software, Version 9. Cary, NC, USA. 2002.

SIWAKOTI M \& TIWARI S. Emerging Needs of Wetlands Protection for the Conservation of Wild Rice Biodiversity in Nepal. Scientific World. 2007; 5(5): 95-99.

SMITH RJ. Weed threshold in southern US rice Oryza sativa. Weed Technology. 1988; 2: 32241.

WAHAB AH \& SUHAIMI O. Padiangin characteristics, adverse effects and methods of its eradication. Teknology Padi. 1991; 8:21-31.

ZEIGLER RS \& BARCLAY A. The relevance of rice. Rice. 2008; 1: 3-10. 